OPEN ACCESS

Edited by:

Ziya Levent Gokaslan, Brown University, United States

Reviewed by: Leonardo Welling Universidade Estadual de Ponta Grossa, Brazi Hiroki Toda, Fukui Red Cross Hospital, Japan

*Correspondence:

Terence Yi Song Liew liew.yisong.terence@gmail.com

Specialty section:

This article was submitted to Neurosurgery,

a section of the journal

Frontiers in Surgery

Received: 23 March 2019

Accepted: 04 June 2019

Published: 03 July 2019

Citation:

Liew TYS, Ng JX, Jayne CHZ, Ragupathi T, Teo CKA and Yeo TT (2019) Changing Demographic Profiles of Patients With Traumatic Brain Injury: An Aging Concern. Front. Surg. 6:37. doi: 10.3389/fsurg.2019.00037

\section{Changing Demographic Profiles of Patients With Traumatic Brain Injury: An Aging Concern}

\author{
Terence Yi Song Liew ${ }^{1 *}$, Jun Xuan $\mathrm{Ng}^{2}$, Chan Hui Zhen Jayne ${ }^{2}$, Tharun Ragupathi ${ }^{2}$, \\ Colin Kok Ann Teo ${ }^{1}$ and Tseng Tsai Yeo ${ }^{1}$ \\ ${ }^{1}$ Division of Neurosurgery, University Surgical Cluster, National University Hospital, Singapore, Singapore, ${ }^{2}$ Yong Loo Lin \\ School of Medicine, National University of Singapore, Singapore, Singapore
}

Background: Trauma continues to be a common cause of mortality in Singapore. By understanding the epidemiology of Traumatic Brain Injury (TBI), healthcare professionals can be better equipped to tackle the increasing socioeconomic burden of disease, adopting better strategies in healthcare planning.

Methodology: A retrospective review of 367 patients admitted with TBI to a tertiary medical institution from January to December 2014 was performed, studying demographic profiles, injury details and outcomes of these patients. Data was retrieved from the National Trauma Registry and the institution's database.

Results: Two hundred thirty-four of the 367 patients included in this study fell into two age groups- -19 to 40 years and $\geq 65$ years. $58 \%$ of the TBI population were aged $>60$. Predominant mechanism of injuries in these groups were road traffic accidents and unwitnessed falls respectively. 39\% of the Elderly group were on antiplatelet/anticoagulant agents $(p<0.001)$. While aggressive surgical intervention was more common in younger patients $(p<0.001)$, the elderly group had significantly longer lengths of hospital stay $(p<0.001)$. Though Glasgow Outcome Scale (GOS) scores at discharge were not significantly different between the two groups, elderly patients showed greater percentages of post-injury improvement subsequently.

Conclusion: The demographics of TBI patients appears to have shifted toward an older population as compared to a decade ago, with an increased incidence of falls, highlighting a huge healthcare concern. We hope that this study will drive further nationwide studies in future, looking at the incidence and prevalence of $\mathrm{TBI}$, and with the focus on tackling preventable causes of TBI.

Keywords: demographics, traumatic brain injury, socio-economic burden, elderly, healthcare planning

\section{INTRODUCTION}

Trauma continues to be the fifth most common cause of mortality in Singapore, contributing to $4.7 \%$ of all deaths in 2014. Of these patients, traumatic brain injury (TBI) accounts for more than fifty percent of all major disability and mortality (1).

Like most developed countries, Singapore faces the issue of an aging population. The Ministry of Social and Family Development estimates that the percentage of residents aged 65 and over has increased significantly from $8.4 \%$ in 2005 to $11.8 \%$ in 2015 and is projected to reach $18.7 \%$ by 2030 . 
Given this aging population, one can expect to see certain population trends-increased numbers of TBI due to falls in elderly, (2-11) and among TBI patients, an increased use of antiplatelet and anticoagulation medications. Similarly, patients are more likely to have existing comorbidities such as hypertension, diabetes, and ischemic heart disease, translating to poorer outcomes $(2,5,10,12-19)$. Correspondingly, there will also be limited economic capacity for placements in hospitals.

The management of TBI continues to put an enormous strain on hospital manpower. With (1) the costs incurred both by the hospitals and families involved in patient care, $(15,20-23)$ and (2) the use of intracranial pressure monitors and extra ventricular drains having risks of device related complications, (24-26) many patients continue to experience effects of TBI long after discharge $(2,3)$. Studies have shown that the long term life expectancy of TBI patients is lower than the general population, $(12,13,16)$ with many of these patients facing chronic disabilities $(13,20,27)$. Studies on the association between TBI and dementia have also started to garner public interest (17).

Age has often been identified as a risk factor for poorer outcomes in TBI $(3,5,8,12,15-19,25,28)$. Older patients tend to have poorer outcomes, regardless of other factors such as Glasgow Coma Scale (GCS) score on admission and mechanism of injury. Though these patients tend to have low impact injuries e.g., falls, an increased severity is noted on computed tomography (CT) scans of the brain (7). This could be due to an increased incidence of cerebral atrophy in the elderly population.

This study aims to assess demographic profiles of the local TBI population and serve as a basis for future comparison with local (10) and international data. Examine institutional implications of an aging population on inpatient TBI socioeconomic burden.

\section{METHODS}

A retrospective cohort study was carried out on patients with isolated TBI. Patients were identified for the period from 1st January 2014 to 31st December 2014 in a single institutionNational University Hospital, Singapore. This data was identified and retrieved from the National Trauma Registry, Singapore, as well as the institution's own patient information database.

For the purpose of our study, patients' TBI severity was classified with the Abbreviated Injury Scale (AIS). The AIS is one of the most commonly used anatomical scales to rate the severity of injuries, including TBIs (29). The AIS can also be used to calculate the Injury Severity Scale (ISS), which is then used to evaluate and prognosticate major trauma or polytrauma. The AIS score ranges from 1, a minor injury, all the way to 6 , an unsurvivable injury. Moderate to severe TBI corresponds to an AIS (Head and/or neck) score of 3-5. We also exclude patients with an AIS score of 3 or more in any other body part, as these other injuries may become a potential confounder in assessment of outcomes of TBI. Two major groups of TBI patients were then considered-(1) ages 18-40, representing a majority of Singapore's working class, and (2) ages above 65, corresponding to the retirement age proposed by the Singapore government. This is in contrast to the local study in 2006, which has defined the cut-off at 60 in view of a lower age of retirement at that time.
The data collected includes patient demographics (age, gender, ethnicity, etc), premorbid status (Activities of Daily Living, ambulance, etc), clinical history and findings on admission (mechanism of injury, volume of intracranial bleed, location of brain injury, etc). Glasgow coma scale (GCS) score, presence of skull fractures, midline shift, vital signs, and relevant laboratory investigations. Details of perioperative and postoperative management were collected as well. Indicators of patient outcome considered were length of hospital stay, ventilator dependent days, Glasgow Outcome Scale (GOS), and mortality. Hospital bill amounts were also traced, for each patient, for comparison.

All statistical analysis was carried out using a standardized statistics software. Comparisons between categorical variables of both groups were assessed using Pearson Chi-squared test or Fisher's Exact Test. Continuous variables were assessed using independent $t$-test and ANOVA (normal distribution) or Mann Whitney $U$-test (non-parametric testing).

\section{RESULTS}

Three patients with moderate to severe TBI were admitted to NUH over a 1-year period from January 2014 to December 2014. The demographical data of these patients are summarized in Table 1. There were 250 males and 117 female patients, with ages ranging from 19 to 98 years old. More than half (58.0\%) of the cohort was aged above 60 . This was significantly higher than historical data, where patients aged above 60 was only reported at $24.6 \%(10)$.

The details of injury of our patients are summarized in Table 2. While a large proportion of these patients $(54.0 \%)$ arrived at the Emergency Department with an AIS (Head and Neck) score of 3, there remained a quarter of the patients who arrived with an AIS (H\&N) of 5, a critical injury with high risk of mortality. Most patients had favorable GCS scores of 14-15, and/or a mild head injury. The most common mechanism of injury was an unwitnessed fall, corresponding to about half of the total patient cohort. Other common mechanisms of injury included road traffic accidents and witnessed falls. The Activities of Daily Living (ADLs) and ambulance status falls within expected proportions. The observed mortality rate was $8.72 \%$.

Our cohort was stratified by age into "Young" and "Elderly" groups, summarized in Table 3 . Of the 167 patients aged $\geq 65$ years old, 93 were male and 74 were female (range, 65-98 years, $77.6 \pm 8.6$ years), giving a male-to-female ratio of $4: 3$. In the younger cohort, aged 19-40 years, the mean age was $30.0 \pm$ 6.3 years, with a male-to-female ratio of $10: 1.62 .7 \%$ of the "Young" group were foreigners predominantly from neighboring countries. Most held work permits for foreign workers.

Major differences were observed in the mechanisms of injury between the two groups. Unwitnessed falls were the most common mechanism of injury in the elderly group, accounting for $70.7 \%$ of injuries. In the young age group, $41.8 \%$ were involved in motor vehicle accidents, keeping consistent with developed country data. A significantly greater proportion of females were observed $(P<0.001)$ in the "Elderly" group (44.3\%) as compared to the "Young" group (9.0\%). 
TABLE 1 | Patient demographics.

\begin{tabular}{|c|c|c|}
\hline & No & $\%$ \\
\hline \multicolumn{3}{|l|}{ GENDER } \\
\hline Male & 250 & 68.1 \\
\hline Female & 117 & 31.9 \\
\hline \multicolumn{3}{|l|}{ RACE } \\
\hline Chinese & 255 & 69.5 \\
\hline Malay & 42 & 11.4 \\
\hline Indian & 34 & 9.3 \\
\hline Others & 36 & 9.8 \\
\hline \multicolumn{3}{|l|}{ AGE GROUP } \\
\hline $0-20$ & 18 & 4.9 \\
\hline $21-40$ & 68 & 18.5 \\
\hline $41-60$ & 68 & 18.5 \\
\hline$>60$ & 213 & 58.0 \\
\hline \multicolumn{3}{|l|}{ NATIONALITY } \\
\hline Singapore & 293 & 79.8 \\
\hline Foreigner & 74 & 20.2 \\
\hline \multicolumn{3}{|l|}{ ADLs } \\
\hline Independent & 336 & 91.6 \\
\hline Assisted & 21 & 5.7 \\
\hline Dependent & 10 & 2.7 \\
\hline \multicolumn{3}{|l|}{ AMBULANCE } \\
\hline Community & 326 & 88.8 \\
\hline Assisted & 28 & 7.6 \\
\hline Homebound & 13 & 3.5 \\
\hline \multicolumn{3}{|c|}{ TABLE 2 | Injury details. } \\
\hline & Number & Percentage (\%) \\
\hline \multicolumn{3}{|l|}{ AIS H\&N } \\
\hline 3 & 198 & 54.0 \\
\hline 4 & 70 & 19.1 \\
\hline 5 & 99 & 27.0 \\
\hline \multicolumn{3}{|l|}{ GCS } \\
\hline$<8$ & 31 & 8.5 \\
\hline $8-13$ & 56 & 15.3 \\
\hline$>13$ & 280 & 76.3 \\
\hline \multicolumn{3}{|c|}{ MECHANISM OF INJURY } \\
\hline Unwitnessed Falls & 186 & 50.7 \\
\hline Witnessed Falls & 63 & 17.2 \\
\hline RTA & 69 & 18.8 \\
\hline Industrial & 7 & 1.9 \\
\hline Fall from height & 31 & 8.5 \\
\hline Assault & 11 & 3.0 \\
\hline \multicolumn{3}{|c|}{ STATUS ON DISCHARGE } \\
\hline Alive & 335 & 91.3 \\
\hline Dead & 32 & 8.7 \\
\hline
\end{tabular}

The type of intracranial injury with the highest incidence in both groups was a subdural hemorrhage (SDH), with incidences of $31.3 \%$ in "Young" and $58.1 \%$ in "Elderly" respectively.
TABLE 3 | Demographic characteristics.

\begin{tabular}{|c|c|c|c|}
\hline & Young $(n=67)$ & Elderly $(n=167)$ & $p$-value \\
\hline Age & $30.0 \pm 6.3$ & $77.6 \pm 8.6$ & \\
\hline Female Gender & $6(9.0 \%)$ & 74 (44.3\%) & $<0.001$ \\
\hline Race & & & $<0.001$ \\
\hline Chinese & 24 (35.8\%) & $141(84.4 \%)$ & \\
\hline Malay & $6(9.0 \%)$ & $13(7.8 \%)$ & \\
\hline Indian & 19 (28.4\%) & $6(3.6 \%)$ & \\
\hline Others & 18 (26.9\%) & 7 (4.2\%) & \\
\hline Smoking & & & 0.261 \\
\hline Smoker & 5 (7.5\%) & 21 (12.6\%) & \\
\hline Non-Smoker & 62 (92.5\%) & 146 (87.4\%) & \\
\hline Alcohol & & & 0.175 \\
\hline Drinker & $2(3.0 \%)$ & 13 (7.8\%) & \\
\hline Non-Drinker & 65 (97.0\%) & 154 (92.2\%) & \\
\hline ADLs & & & 0.006 \\
\hline Independent & 66 (98.5\%) & 139 (83.2\%) & \\
\hline Assisted & $1(1.5 \%)$ & 23 (13.8\%) & \\
\hline Dependent & $0(0.0 \%)$ & 5 (3.0\%) & \\
\hline Ambulance & & & $<0.001$ \\
\hline Community & 66 (98.5\%) & $119(71.3 \%)$ & \\
\hline Assisted & $1(1.5 \%)$ & 34 (20.4\%) & \\
\hline Homebound & 0 (0.0\%) & $14(8.4 \%)$ & \\
\hline Premorbid ASA & & & $<0.001$ \\
\hline 1 & 60 (89.6\%) & 19 (11.4\%) & \\
\hline 2 & 7 (10.5\%) & 75 (44.9\%) & \\
\hline 3 & $0(0.0 \%)$ & 70 (41.9\%) & \\
\hline 4 & 0 (0.0\%) & $3(1.8 \%)$ & \\
\hline Anti-coag/platelets & & $\varangle 0.001$ & \\
\hline None & 67 (100.0\%) & 102 (61.1\%) & \\
\hline Anticoagulants & $0(0.0 \%)$ & $12(7.2 \%)$ & \\
\hline Antiplatelets & $0(0.0 \%)$ & 52 (31.1\%) & \\
\hline Nationality & & & $<0.001$ \\
\hline Singapore & 25 (37.3\%) & $161(96.4 \%)$ & \\
\hline Foreigner & 42 (62.7\%) & 6 (3.6\%) & \\
\hline
\end{tabular}

However, the "Young" group had an extradural hemorrhage $(\mathrm{EDH})$ incidence of $26.9 \%$ while that of the "Elderly" group was $10.8 \%$. Elderly patients were also more prone to multiple bleed locations (66.5\%). The incidence of skull fractures in the "Young" group was higher (64.2\%) than in the "Elderly" group $(29.3 \%)(P<0.001)$.

A significant proportion $(P<0.001)$ of the "Elderly" group were on antiplatelet agents $(31.1 \%)$ or anticoagulants $(7.2 \%)$, which corresponds with the pre-morbid ASA findings of this group where most had a score of 2 and above (Table 3). The increased use of anticoagulant and antiplatelet agents is made more evident when considering the PTT values and incidence of thrombocytopenia in both groups. Elderly patients tend to be more coagulopathic and thrombocytopenic than their younger counterparts (Table 4).

Surgical intervention was more commonly administered in the "Young" group with more than $40 \%$ receiving some form of surgical treatment compared to $20 \%$ in the "Elderly" group 
TABLE 4 | Laboratory results.

\begin{tabular}{lccr}
\hline & Young $(\boldsymbol{n}=\mathbf{6 7})$ & Elderly $(\boldsymbol{n}=\mathbf{1 6 7})$ & $\boldsymbol{p}$-value \\
\hline $\mathrm{INR}$ & $1.1 \pm 0.3$ & $1.2 \pm 0.4$ & 0.479 \\
$\mathrm{PTT}(\mathrm{s})$ & $27.8 \pm 3.4$ & $30.0 \pm 4.3$ & $<0.001$ \\
$\mathrm{pH}$ & $7.4 \pm 0.1$ & $7.4 \pm 0.1$ & 0.998 \\
$\mathrm{Hb}(\mathrm{g} / \mathrm{dL})$ & $14.6 \pm 1.9$ & $12.3 \pm 2.1$ & $<0.001$ \\
Thrombocytopenia & $1(1.5 \%)$ & $23(13.8 \%)$ & 0.008 \\
$\mathrm{Na}(\mathrm{mmol} / \mathrm{L})$ & $138.8 \pm 16.6$ & $138.0 \pm 4.6$ & 0.694 \\
\hline
\end{tabular}

TABLE 5 | Surgical intervention.

\begin{tabular}{lccr}
\hline & Young $(\boldsymbol{n}=\mathbf{6 7})$ & Elderly $(\boldsymbol{n}=\mathbf{1 6 7 )}$ & $\boldsymbol{p}$-value \\
\hline Whole Blood given & $1(1.5 \%)$ & $2(1.2 \%)$ & 0.856 \\
FFP given & $0(0.0 \%)$ & $40(24.0 \%)$ & $<0.001$ \\
Time to Surgery (h) & $15.4(2-144)$ & $52.4(2-576)$ & 0.156 \\
Surgery Type & & & $<0.001$ \\
$\quad$ None & $37(55.2 \%)$ & $134(80.2 \%)$ & \\
Craniotomy & $1(1.5 \%)$ & $0(0.0 \%)$ & \\
Craniectomy & $10(14.9 \%)$ & $17(10.2 \%)$ & \\
Burr Hole & $6(9.0 \%)$ & $10(6.0 \%)$ & \\
$\quad$ Others & $13(19.4 \%)$ & $6(3.6 \%)$ & \\
& &
\end{tabular}

(Table 5). Younger patients also received more aggressive forms of surgical intervention, e.g., craniectomies $(P<0.001)$. This can be explained by the increased SDH incidence in the older group, as most of these patients would receive conservative treatment as compared to the young group where significant proportions had an EDH (Table 6). The shorter time to surgery for the young group can also be explained by the urgency of surgery for $\mathrm{EDH}$ as compared to $\mathrm{SDH}$, which are more common in elderly TBI. Elderly patients (24.0\%) also received more blood product support than the younger patients $(0.0 \%)$.

Comparison of outcomes of TBI between the two groups showed a higher incidence of poorer outcomes in the "Elderly" group (Table 7). This group tended to require much longer lengths of stay $(P<0.001)$. However, there was no significant difference in terms of cost of care between both groups, which is surprising in view of the significant longer length of stay. A larger proportion of elderly patients also had lower GOS scores upon discharge compared to younger patients in the cohort, demonstrating lower rates of functional improvement following TBI. However, subsequent GOS scores for the "Elderly" group revealed higher percentages of post-TBI functional improvement than the "Young" group $(P<0.01)$, suggesting that elderly patients require a longer time to regain normal function.

\section{DISCUSSION}

\section{Age Demographics}

In this study, the race and nationality are comparable with recently published data on the Singapore population trends. However, in contrast to previous studies done in Singapore in 2006, (10) a significant difference in age demographics was noted. While these studies showed a peak in the 20-40 age group, $(10,30)$ our study showed a peak in the above 60 age group.
TABLE 6 | Injury.

\begin{tabular}{|c|c|c|c|}
\hline & Young $(n=67)$ & Elderly $(n=167)$ & $p$-value \\
\hline Mechanism of injury & & & $<0.001$ \\
\hline Unwitnessed fall & 5 (7.5\%) & 118 (70.7\%) & \\
\hline Witnessed Fall & $10(14.9 \%)$ & $31(18.6 \%)$ & \\
\hline RTA & $28(41.8 \%)$ & $12(7.2 \%)$ & \\
\hline Industrial & $4(6.0 \%)$ & $0(0.0 \%)$ & \\
\hline Fall from height & 15 (22.4\%) & $5(3.0 \%)$ & \\
\hline Assault & $5(7.5 \%)$ & $1(0.6 \%)$ & \\
\hline Intracranial Injury & & & 0.001 \\
\hline None & 7 (10.5\%) & $8(4.8 \%)$ & \\
\hline $\mathrm{EDH}$ & $18(26.9 \%)$ & $18(10.8 \%)$ & \\
\hline $\mathrm{SDH}$ & 21 (31.3\%) & 97 (58.1\%) & \\
\hline SAH & $13(19.4 \%)$ & $21(12.6 \%)$ & \\
\hline $\mathrm{ICH}$ & $6(9.0 \%)$ & $22(13.2 \%)$ & \\
\hline Others & 2 (3.0\%) & $1(0.6 \%)$ & \\
\hline Location of injury & & & 0.024 \\
\hline None & 7 (10.5\%) & $9(5.4 \%)$ & \\
\hline Frontal & 16 (23.9\%) & 26 (15.6\%) & \\
\hline Temporal & 7 (10.5\%) & $10(6.0 \%)$ & \\
\hline Parietal & $6(9.0 \%)$ & 5 (3.0\%) & \\
\hline Occipital & 2 (3.0\%) & $6(3.6 \%)$ & \\
\hline Multiple & 29 (43.3\%) & 111 (66.5\%) & \\
\hline Skull Fractures Present & 43 (64.2\%) & 49 (29.3\%) & $<0.001$ \\
\hline Midline shift Present & $13(19.4 \%)$ & $35(21.0 \%)$ & 0.790 \\
\hline Amount of shift & $5.6 \pm 4.9$ & $8.8 \pm 7.2$ & 0.079 \\
\hline AIS (H\&N) & & & 0.061 \\
\hline 3 & $43(64.2 \%)$ & 80 (47.9\%) & \\
\hline 4 & $12(17.9 \%)$ & 37 (22.2\%) & \\
\hline 5 & 12 (17.9\%) & 50 (29.9\%) & \\
\hline \multicolumn{4}{|l|}{ AIS (Others) } \\
\hline 3 & 0 & 0 & \\
\hline 4 & 0 & 0 & \\
\hline 5 & 0 & 0 & \\
\hline GCS & & & 0.112 \\
\hline Mild & 49 (73.1\%) & $140(83.8 \%)$ & \\
\hline Moderate & $11(16.4 \%)$ & $13(7.8 \%)$ & \\
\hline Severe & $7(10.4 \%)$ & $14(8.4 \%)$ & \\
\hline Hypotensive & $1(1.5 \%)$ & $4(2.4 \%)$ & 0.666 \\
\hline Tachycardic & $4(6.0 \%)$ & 18 (10.8\%) & 0.255 \\
\hline Tachypneic & 14 (20.9\%) & $19(11.4 \%)$ & 0.059 \\
\hline Febrile & 0 (0.0\%) & 7 (4.2\%) & 0.089 \\
\hline On Oxygen Support & $7(10.5 \%)$ & $13(7.8 \%)$ & 0.510 \\
\hline
\end{tabular}

Furthermore, while a similar earlier study showed road traffic accidents as the most common cause of TBI locally, (10) our study showed a shift in mechanism of injury to falls, which can be attributed to an increasingly aging population in Singapore.

Nations around the world are facing the crisis of an aging population. Population data from United Nations have shown that the number of persons aged above 60 has increased significantly in many countries, and the rate of growth in number of older persons is expected to accelerate in the coming decades. It is estimated that the number of persons aged above 60 globally 
TABLE 7 | Outcomes.

\begin{tabular}{|c|c|c|c|}
\hline & Young $(n=67)$ & Elderly $(n=167)$ & $p$-value \\
\hline Length of Stay (Days) & $8.5(1-97)$ & $20.4(1-388)$ & $<0.001$ \\
\hline $\begin{array}{l}\text { Ventilator dependent } \\
\text { days }\end{array}$ & $4.5(1-8)$ & $6.5(2-20)$ & 0.679 \\
\hline Readmission & $3(4.5 \%)$ & $12(7.2 \%)$ & 0.445 \\
\hline GOS Discharge & & & 0.030 \\
\hline 5 & $51(76.1 \%)$ & 96 (57.5\%) & \\
\hline 4 & 12 (17.9\%) & $38(22.8 \%)$ & \\
\hline 3 & $2(3.0 \%)$ & $15(9.0 \%)$ & \\
\hline 2 & $0(0.0 \%)$ & $0(0.0 \%)$ & \\
\hline 1 & $2(3.0 \%)$ & 18 (10.8\%) & \\
\hline GOS (3 months) & & & 0.011 \\
\hline 5 & 55 (82.1\%) & 107 (64.1\%) & \\
\hline 4 & $7(10.5 \%)$ & $25(15.0 \%)$ & \\
\hline 3 & $0(0.0 \%)$ & $11(6.6 \%)$ & \\
\hline 2 & $0(0.0 \%)$ & $0(0.0 \%)$ & \\
\hline 1 & 2 (3.0\%) & $19(11.4 \%)$ & \\
\hline Mortality & $2(3.0 \%)$ & $13(7.9 \%)$ & 0.175 \\
\hline $\begin{array}{l}\text { Average Hospital Bill } \\
\text { Size }\end{array}$ & $\begin{array}{c}8227.0 \\
(422-125,932)\end{array}$ & $\begin{array}{c}10412.7 \\
(422-164,467)\end{array}$ & 0.403 \\
\hline
\end{tabular}

is expected to increase from 841 million people in 2013 to above 2 billion in 2050 .

Our data showed that older patients tended to be more coagulopathic and thrombocytopenic, given that elderly patients are more prone to diseases such as stroke and malignancies that can cause such bleeding disorders (31). It is thus reasonable to expect to see an increased number of older patients presenting with TBI in the emergency department.

\section{Falls}

Singapore's elderly population is one of the fastest growing in the world, possibly resulting in increasing incidences of fall-related cases seen in local hospitals (32). Though the observed mortality rates of $8.72 \%$ were lower than previously reported studies, (33) fall prevention remains critical in preventing such admissions, and will greatly decrease the number of TBI patient admissions. More studies in the community to identify ways to prevent falls in the elderly are warranted. Some commonly used items include grab bars and anti-slip mats in toilets as well as proper lighting in households. Though existing fall prevention programs aim to prevent fragility fractures, the same consideration has yet to be given to head impact (4). Caregiver employment for patients who live alone and $\mathrm{ADL}$ dependence can also be explored, since a large proportion of TBI patients suffer unwitnessed falls. Also, there is a trend toward more conservative management for older TBI patients. More studies will need to be conducted to weigh the pros and cons of a surgical approach of treating these patients in view of an increasing lifespan of the general population.

\section{TBI in Younger Patients}

While a larger proportion of TBI patients are older persons, our study still shows a significant proportion of younger patients with TBI. Many of these patients suffer from either a work injury (such as fall from height or industrial accidents) or a road traffic accident. More skull fractures were observed in young patients-this is consistent with the observation that younger patients tended to sustain higher impact injuries like road traffic accidents, especially as pedestrians involved in these accidents (34).

Though much has been done to reduce the incidence and impact of work related injuries, (35) other options can be considered. Foreign workers working here must be provided with medical insurance of adequate coverage based on their industry, and much has already been done to promote helmet use in the construction industry (22). However, there is still a large number of foreign workers suffering from TBI each year. More studies should be done to identify areas for improvement to reduce the incidence of work-related TBI. One example would be working hours, where a study has shown that there were significantly more TBIs at specific times of the day (36).

Road traffic accidents have been and will likely always remain a major cause of moderate to severe TBI. Recently published local data by the Singapore Police Force in 2015 has shown a decline in number of road traffic accidents over the past four years. However, the number of casualties from such accidents still remain high. A developed country study has shown that implementation of motorcycle helmet law results in a lower incidence of TBI due to motorcycle accidents as compared with states in which such laws were not implemented, (37) suggesting that tougher enforcement of seat belt use and laws against drink driving is necessary.

\section{A Sustainable Healthcare Model}

A population report from Singapore Ministry of Health in 2010 identified that falls are the main etiology of TBI among elderly in Singapore. This etiology and its associated outcomes have not changed in 10 years $(10,38)$. This phenomenon is likely to continue as Singapore's population ages, despite efforts to mitigate falls in elderly.

A 1985 study by Eisenberg et al looked at the changes in the demographic profiles of patients that suffered from Spinal Cord Injuries (SCI) (39). In the study, it has been shown that while more than $70 \%$ of patients with SCI fall within the 17-35 age group, it is the long-term SCI survivors, or "veterans," that require the most long-term care. Eisenberg et al. suggest that more healthcare resources should be channeled to benefit this group of patients.

Based on the epidemiologic transition theory, we are at The Age of Degenerative and Man-Made Diseases (40). This suggests that as science and healthcare progresses, overall mortality will decline and approach stability at a relatively low level (40). This also implies that the average life expectancy will increase, leading to more morbidity (degenerative and manmade diseases).

Given the predictability of TBI incidence in elderly, our research findings may form the basis of a stable healthcare model. The extent of healthcare resource allocation toward the elderly group can be better managed so as to achieve cost-efficiency. 


\section{STRENGTHS AND LIMITATIONS}

The main strengths of this study are the detailed focus on the demographics of patients with TBI, with focus on the mechanisms of injury, treatment and morbidity and mortality rates of different age groups. This study also puts into focus areas of interest in healthcare planning, with highlights on certain preventive measures that can be undertaken to reduce incidence as well as morbidity and mortality of TBI. This study includes all patients admitted for major TBI, thus eliminating selection and inclusion bias. The main limitations of this study will be that this is a single center study, with comparisons to only local data. This study also has a relatively small sample size. Further studies can be performed in future with larger sample sizes for more accurate comparisons.

\section{CONCLUSION}

TBI in elderly has resulted in a huge socioeconomic burden to society. More can be done to decrease the number of elderly TBI patients. It seems that this problem will only grow in both medical and socioeconomic aspects in years to come (15). As the

\section{REFERENCES}

1. Leong MKF, Mujumdar S, Raman L, Lim YH, Chao TC, Anantharaman V. Injury related deaths in Singapore. Hong Kong J. Emerg Med. (2003) 10:88-96. doi: 10.1177/102490790301000205

2. Albrecht JS, McCunn M, Stein DM, Simoni-Wastila L, Smith GS. Sex differences in mortality following isolated traumatic brain injury among older adults. J Trauma Acute Care Surg. (2016) 81:486-92. doi: 10.1097/TA.0000000000001118

3. Haring RS, Narang K, Canner JK, Asemota AO, George BP, Selvarajah S, et al. Traumatic brain injury in the elderly: morbidity and mortality trends and risk factors. J Surg Res. (2015) 195:1-9. doi: 10.1016/j.jss.2015.01.017

4. Büchele G, Rapp K, König HH, Jaensch A, Rothenbacher D, Becker C, et al. The risk of hospital admission due to traumatic brain injury is increased in older persons with severe functional limitations. J Am Med Dir Assoc. (2016) 17:609-12. doi: 10.1016/j.jamda.2016.02.032

5. Shivaji T, Lee A, Dougall N, McMillan T, Stark C. The epidemiology of hospital treated traumatic brain injury in Scotland. BMC Neurol. (2014) 14:2. doi: 10.1186/1471-2377-14-2

6. Siew KL, Ng YS, Nalanga AJ, Tan YL, Bok CW. A pilot project of early integrated traumatic brain injury rehabilitation in Singapore. Rehabil Res Pract. (2014) 2014:950183. doi: 10.1155/2014/950183

7. Herou E, Romner B, Tomasevic G. Acute traumatic brain injury: mortality in the elderly. World Neurosurg. (2015) 83:996-1001. doi: 10.1016/j.wneu.2015.02.023

8. Monsef Kasmaei V, Asadi P, Zohrevandi B, Raouf MT. An epidemiologic study of traumatic brain injuries in emergency department. Emerg (Tehran). (2015) 3:141-5

9. Joseph B, Haider AA, Pandit V, Tang A, Kulvatunyou N, O’Keeffe T, et al. Changing paradigms in the management of 2184 patients with traumatic brain injury. Ann Surg. (2015) 262:440-8. doi: 10.1097/SLA.0000000000001418

10. Lee KK, Seow WT, Ng I. Demographical profiles of adult severe traumatic brain injury patients: implications for healthcare planning. Singapore Med J. (2006) 47:31-6.

11. Abelson-Mitchell N. Epidemiology and prevention of head injuries: literature review. J Clin Nurs. (2008) 17:46-57. doi: 10.1111/j.1365-2702.2007.01941.x

12. Brooks JC, Shavelle RM, Strauss DJ, Hammond FM, Harrison-Felix CL. Long-term survival after traumatic brain injury part I: external awareness of TBI in the elderly grows, better ideas, and innovative strategies are necessary to prevent unwitnessed falls in the elderly. This will indirectly translate to a lower healthcare cost and a lower socioeconomic burden of TBI in Singapore. Perhaps with prospective data, a standardized outcome assessment for TBI can be formulated, one that can accurately determine the outcomes of patients when they are first seen in the Emergency Department.

\section{DATA AVAILABILITY}

The raw data supporting the conclusions of this manuscript will be made available by the authors, without undue reservation, to any qualified researcher.

\section{ETHICS STATEMENT}

Domain Specific Review Board, Reference number: \#2015/01173.

\section{AUTHOR CONTRIBUTIONS}

All authors listed have made a substantial, direct and intellectual contribution to the work, and approved it for publication. validity of prognostic models. Arch Phys Med Rehabil. (2015) 96:9949. doi: 10.1016/j.apmr.2015.02.003

13. Fuller GW, Ransom J, Mandrekar J, Brown AW. Long-term survival following traumatic brain injury: a population-based parametric survival analysis. Neuroepidemiology. (2016) 47:1-10. doi: 10.1159/000445997

14. Hammond FM, Horn SD, Smout RJ, Seel RT, Beaulieu CL, Corrigan JD, et al. Rehospitalization during 9 months after inpatient rehabilitation for traumatic brain injury. Arch Phys Med Rehabil. (2015) 96:3309. doi: 10.1016/j.apmr.2014.09.041

15. Gilasi HR, Soori H, Yazdani S, Taheri Tenjani P. Fall-related injuries in community dwelling older adults in Qom province, Iran, 2010-2012. Arch Trauma Res. (2015) 4:e22925. doi: 10.5812/atr.22925

16. Brooks JC, Shavelle RM, Strauss DJ, Hammond FM, Harrison-Felix CL. Longterm survival after traumatic brain injury; part II: life expectancy. Arch Phys Med Rehabil. (2015) 96:1000-5. doi: 10.1016/j.apmr.2015.02.002

17. Johnson VE, Stewart W. Traumatic brain injury: age at injury influences dementia risk after TBI. Nat Rev Neurol. (2015) 11:128-30. doi: 10.1038/nrneurol.2014.241

18. Vijay K, Monica SV, Brianna M, Rowhani RA. Demographic and clinical risk factors associated with hospital mortality after isolated severe traumatic brain injury: a cohort study. J Intensive Care. (2015) 3:46. doi: 10.1186/s40560-015-0113-4

19. Tran TM, Fuller AT, Kiryabwire J, Mukasa J, Muhumuza M, Ssenyojo H, et al. Distribution and characteristics of severe traumatic brain injury at Mulago National Referral Hospital in Uganda. World Neurosurg. (2015) 83:269-77. doi: 10.1016/j.wneu.2014.12.028

20. Wrona RM. The use of state workers' compensation administrative data to identify injury scenarios and quantify costs of work-related traumatic brain injuries. J Safety Res. (2006) 37:75-81. doi: 10.1016/j.jsr.2005. 08.008

21. Mujuru P, Singla L, Helmkamp J, Bell J, Hu W. Evaluation of the burden of logging injuries using West Virginia workers' compensation claims data from 1996 to 2001. Am J Ind Med. (2006) 49:1039-45. doi: 10.1002/ajim. 20389

22. Naumann RB, Marshall SW, Proescholdbell SK, Austin A, Creppage K. Impact of North Carolina's motorcycle helmet law on hospital admissions and charges for care of traumatic brain injuries. N C Med J. (2015) 76:705. doi: $10.18043 / \mathrm{ncm} \cdot 76.2 .70$ 
23. Joseph B, Pandit V, Haider AA, Kulvatunyou N, Zangbar B, Tang A. Improving hospital quality and costs in nonoperative traumatic brain injury: the role of acute care surgeons. JAMA Surg. (2015) 150:86672. doi: 10.1001/jamasurg.2015.1134

24. Servadei F, Picetti E. Intracranial pressure monitoring and outcome in traumatic brain injury: the probe does matter? World Neurosurg. (2015) 83:732-3. doi: 10.1016/j.wneu.2015.01.031

25. Kasotakis G, Michailidou M, Bramos A, Chang Y, Velmahos G, Alam H, et al. Intraparenchymal vs extracranial ventricular drain intracranial pressure monitors in traumatic brain injury: less is more? J Am Coll Surg. (2012) 214:950-7. doi: 10.1016/j.jamcollsurg.2012.03.004

26. Yuan Q, Wu X, Sun Y, Yu J, Li Z, Du Z. Impact of intracranial pressure monitoring on mortality in patients with traumatic brain injury: a systematic review and meta-analysis. J Neurosurg. (2015) 122:74-87. doi: 10.3171/2014.10.JNS1460

27. Salem AM, Jaumally BA, Bayanzay K, Khoury K, Torkaman A. Traumatic brain injuries from work accidents: a retrospective study. Occup Med. (2013) 63:358-60. doi: 10.1093/occmed/kqt037

28. Chang VC, Guerriero EN, Colantonio A. Epidemiology of work-related traumatic brain injury: a systematic review. Am J Ind Med. (2015) 58:35377. doi: 10.1002/ajim.22418

29. Lesko MM, Woodford M, White L, O’Brien SJ, Childs C, Lecky FE. Using abbreviated injury scale (AIS) codes to classify Computed Tomography (CT) features in the marshall system. BMC Med Res Methodol. (2010) 10:72. doi: 10.1186/1471-2288-10-72

30. Gan BK, Lim JH, Ng IH. Outcome of moderate and severe traumatic brain injury amongst the elderly in Singapore. Ann Acad Med Singapore. (2004) 33:63-7.

31. Schoeneberg C, Probst T, Schilling M, Wegner A, Hussmann B, Lendemans S. Mortality in severely injured elderly patients: a retrospective analysis of a German level 1 trauma center (2002-2011). Scand J Trauma Resusc Emerg Med. (2014) 22:45. doi: 10.1186/s13049-0140045-3

32. Stiefel MF, Spiotta A, Gracias VH, Garuffe AM, Guillamondegui $\mathrm{O}$, Maloney-Wilensky E, et al. Reduced mortality rate in patients with severe traumatic brain injury treated with brain tissue oxygen monitoring. J Neurosurg. (2005) 103:805-11. doi: 10.3171/jns.2005.103. 5.0805
33. Yeo YY, Lee SK, Lim CY, Quek LS, Ooi SB. A review of elderly injuries seen in a Singapore emergency department. Singapore Med J. (2009) 50:278-83. Available online at: http://www.smj.org.sg/sites/default/files/5003/5003a6.pdf

34. Majdan M, Mauritz W, Wilbacher I, Janciak I, Brazinova A, Rusnak M. Traumatic brain injuries caused by traffic accidents in five European countries: outcome and public health consequences. Eur J Public Health. (2013) 23:682-7. doi: 10.1093/eurpub/cks074

35. Kica J, Rosenman KD. Surveillance for work-related skull fractures in Michigan. J Safety Res. (2014) 51:49-56. doi: 10.1016/j.jsr.2014.09.003

36. Colantonio A, Mroczek D, Patel J, Lewko J, Fergenbaum J, Brison R. Examining occupational traumatic brain injury in Ontario. Can J Public Health. (2010) 101(Suppl 1):58-62. doi: 10.1007/BF03403848

37. Olsen CS, Thomas AM, Singleton M, Gaichas AM, Smith TJ, Smith GA. Motorcycle helmet effectiveness in reducing head, face and brain injuries by state and helmet law. Inj Epidemiol. (2016) 3:8. doi: 10.1186/s40621-016-0072-9

38. Wee JZ, Yang YR, Lee QY, Cao K, Chong CT. Demographic profile and extent of healthcare resource utilisations of patients with severe traumatic brain injury: still a major public health problem. Singapore Med J. (2016) 57:491-6. doi: 10.11622/smedj.2015162

39. Eisenberg MG, Tierney DO. Changing demographic profile of the spinal cord injury population: implications for health care support systems. Paraplegia. (1985) 23:335-43. doi: 10.1038/sc.1985.53

40. Omran AR. The epidemiologic transition: a theory of the epidemiology of population change. Milbank Q. (2005) 83:731-57. doi: 10.1111/j.1468-0009.2005.00398.x

Conflict of Interest Statement: The authors declare that the research was conducted in the absence of any commercial or financial relationships that could be construed as a potential conflict of interest.

Copyright (c) 2019 Liew, Ng, Jayne, Ragupathi, Teo and Yeo. This is an open-access article distributed under the terms of the Creative Commons Attribution License (CC $B Y)$. The use, distribution or reproduction in other forums is permitted, provided the original author(s) and the copyright owner(s) are credited and that the original publication in this journal is cited, in accordance with accepted academic practice. No use, distribution or reproduction is permitted which does not comply with these terms. 